\title{
Editorial: Borrowing, quotation, sampling and plundering
}

\section{INTRODUCTION}

As the call for articles for this issue remarked, the activity of borrowing is ubiquitous within the arts. Music, like visual and literary arts, demonstrates an extensive variety of ways recycling existing material (recordings, scores, music, sounds and ideas) can assist and inspire the generation of new art. Focusing the lens upon sound borrowing and its manifestations within the realm of sonic arts presented a theme that surprisingly had not been addressed previously, which seems at odds with the fact that sound borrowing practices (e.g., sampling) have been in operation for decades, and borrowing or stealing in music for centuries.

\section{FOCUS OF ENQUIRY}

The focus of this enquiry covers a broad spectrum of borrowing practices including the transfer of existing recordings of music and sound, sourcing of audio material from sound archives, libraries, sound objects previously used by other composers and copyleft imports. Surveying the landscape of sound-based music for instances of existing source import uncovered an unanticipated and extensive body of work that engaged with borrowing in vastly different ways. Looking into this topic and existing repertoire, many cases of electroacoustic music emerged that searched further afield to distant times and practices for their music imports. Assessing and appreciating how such historical or culturally significant material made the leap into current and contemporary music presents a fascinated before and after reworking, and a unique entry point to engage and understand these works. Sampling practices demonstrating wide historical and cultural transitions into the contemporary realm provide a ready-made 'portal for music discovery', where one can find music within music, and sound within sound. This is an exciting process to witness and as a result of turning attention to such works, music previously unknown to the listener have come to the fore. Such works naturally encourage wider listening to fully grasp the meaning, especially when it is intentional that listeners catch the reference. Familiarity with the original musics/sound can fuel fascination and curiosity, providing a point of contemplation for both the original source and its reworking. Thus, works of this kind inherently develop a dual-faced existence (that of the original and that of the newly generated work). Interest in sound and musical borrowing has developed into a number of questions regarding how such imports came to be, what function historical sounds and music play within new contexts and what sort of sonic surroundings these existing elements now call home.

\section{RATIONALE AND AIMS}

A clear rationale to create this themed issue of Organised Sound is apparent when viewing electroacoustic practices heavily reliant on recorded sound. Sampling, in some shape or form, is at the heart of many electroacoustic works and without the import of sourced sound, there would not be the wealth of compositions around as there are today. Sampling is certainly not a practice exclusive to electroacoustic works, just think of hip-hop music and DJ-ing, but what is notable is that electroacoustic music utilises sampling in a number of unique ways:

- The treatment and transformation stage is a regular and go-to practice to derive new sound from sonic imports.

- The genre often escapes legal restrictions and regulations with regards to borrowed material due to their oblique presence; thus in some cases, samples can often hide and be buried within a work unbeknown to listeners

- Terminology used to describe borrowings within electroacoustic music carries different meaning from that in commercial, popular or instrumental genres.

- No sound or music appears to be off limits when it comes to sampling in the electroacoustic music domain, which is not subject to the same architectonic constraint as found in much acoustic/ commercial music.

With this in mind, it was evident that greater discussion on this topic was required to deepen the theoretical frame. Returning briefly to terminology, there are clear differences in vocabulary application across musical genres. Just think of the words 'quotation', 'inter-textuality' and 'copying' and their very 
different meanings and significance in the fields of instrumental, popular and electroacoustic music. Interchangeability amongst terms runs rife within my own article, 'The Terminology of Borrowing', signalling the lack of consensus amongst the electroacoustic music community to describe borrowing procedures. Addressing this issue via an assessment of programme notes and composer interviews, the issue is further complicated with perceptions of borrowing articulated as a vehicle to vindicate one's actions, establishing a shield against the possible negative connotations of theft or appropriation. This article also demonstrates how words enter from surrounding musical discourses as a means of offering useful external perspectives to sampling procedures take for example the terms 'remix' or 'mash-up'.

The aim of this issue is not only to delineate different types of musical borrowing cases, and discuss terminology confusions, but also to consider sound itself as something to be borrowed. The guest editor has both witnessed and participated in collaborative projects specifically conceived to share sounds; for example, the Luc Ferrari Presque Rein Competition, ${ }^{1}$ which calls for new works created using the Luc Ferrari's sound archives -'These sound files were collected during the digitization of Luc Ferrari's magnetic archives.' ${ }^{2}$ The works produced from this competition all negotiate the use of borrowed materials made available, including field recordings, processed sound material and even compositional project material. These dated and iconic sound materials find new homes within a variety of contexts and they significantly motivate composers to connect with the work of Ferrari and his aesthetic.

Further to this, first-hand experience in establishing the Instruments INDIA composition commissioning project $(2012-16)^{3}$ presents a venture that aimed to stimulate more composers to engage with sound borrowings, this time of a cultural nature. Bringing cultural considerations into the borrowing discussion instantly multiplies the questions one can pose. The territory is often tip-toed upon to bypass contentious

${ }^{1}$ Luc Ferrari archive http://lucferrari.com/en/presque-rien-prize/ (accessed December 2018).

${ }^{2}$ Luc Ferrari website content: http://lucferrari.com/en/presquerien-prize/

${ }^{3}$ The Instruments INDIA commissioning project was initiated in 2015-16 calling for proposals from sonic arts practitioners looking to use the Instruments INDIA sound archive. The archive contained approximately 4.5 hours of Indian musical instrument sound recordings made by Blackburn in 2012-13 with 28 contributing musicians. Three artists completed the project (composers Ish Sherawat, Greg Dixon and Steven Naylor) and presented their compositions (a range of fixed media works - multichannel and stereo, and a new instrument, 'The Space Regenerator' - were all inspired from engagement with the archive) and premiered these new works in 2016 in Liverpool. conversations about offence and disrespectful borrowing, but it is on the contrary, as Steven Naylor discovers in 'Borrowed for Permanent Use: The Instruments INDIA commission' that, for him, the process of using Indian musical instrument samples in his composition Rivers (2017) put to bed the characteristic 'minefield' label associated with cultural appropriation, and instead enabled him to take on a more positive outlook through connecting with a wider audience in meaningful ways.

\section{ORIGINALITY VERSUS BORROWING}

Considering 'originality' is a useful opposition to the borrowing discussion so far and one could ask what originality looks like within the electroacoustic domain where borrowing is concerned. A publicity slogan for a concert season at a local conservatoire read 'Does originality actually exist or do we all simply build from what we have seen and heard?" ${ }^{4}$ With this in mind, does borrowing existing music and sound material override the composer's claim for originality or authorship? This has importantly led to a thought regarding sole authorship that has been percolating behind the scenes of this issue. Studying borrowing has had the fortunate upshot of demonstrating composition as a communal activity, rather than a singular practice. Sean Hallowell reconfirms this perspective in his article 'Towards a Phenomenology of Musical Borrowing', stating: 'Every act of musical borrowing constitutes a musical community.' Drawing upon influence, existing sounds, musical practices and processes enables new music to emerge. When we borrow, we continue, develop and evolve existing materials, traditions and influence into new shapes and forms. Observing movements of sound and existing music from one context to the next, as this issue thoroughly demonstrates, provides a fairly watertight challenge to auteur theory, where the composer is viewed as sole creator. This unrealistic impression of the composer locked within a vacuum of his or her own genius is dismantled instantly. Ultimately this could mean that there is no singular authorship within sound-based music! Beyond the actual activity of sound gathering, composing itself is a permutation of influences, context, culture and experiences. Traditions of composing are passed down or sideways and thinking about composition as more of a communal, shared and inherited practice, fuelled by those before us, is a beneficial and refreshing perspective running throughout this issue.

${ }^{4}$ Royal Northern College of Music (RNCM) concert series publication flyer, Autumn/Winter 2018. 


\section{NUANCES}

Some repertoire works encountered on this journey have involved borrowings of a less overt nature, sometimes even hidden on first listening. There are musics that borrow but do not show any observable signs of the original source. These examples can be difficult to come by, except through composer conversations or subtle hints in programme notes. In these cases, does the borrowing act become redundant or irrelevant? This may only be answered on a case-by-case basis, and certain works may pose more ethical concerns than others for their lack of disclosure on the topic. Works where borrowing is a hidden process are perhaps more commonplace that we think, due to the sound-based makeup of electroacoustic music; sound must be sourced from somewhere (bar those works using synthesis) and that 'somewhere' may be existing recordings of sound and/or music. There are also those works where borrowings are clearly noticed but go uncredited or unannounced. Consider Parmerud's acousmatic work Necropolis: City of the Dead (2011) and Kreidler's performance work Product Placement (2008) both of which borrow widely from different sources in a single work (the latter being a more extreme example containing 70,200 samples in 33 seconds, described as a 'nightmare for GERMAN RIAA'5). These particular works raise questions about the relative ease of sourcing borrowed sound material, which links with considerations of legal aspects of borrowing in the wider sense of the term. John Oswald is well known within this discussion for probing issues of sampling, copyright and ownership, while deriving an entire musical practice as an act of protest against the illegal nature of musical imports. His contribution to the field also importantly questions the idea of authorship of both a new piece or a sound. His centrality to this discussion should be remembered here for its unique qualities, its contextual referencing power and those carefully constructed ironies made through his 'mega-editing process[es]' (Lacasse 2000: 52) and procedures. The lineage of plunderphonics trails on, spilling from the territory of popular music, electroacoustic practices, the music industry and legal boundaries; the latter of which still remains a fuzzy, hard-to-pin-down aspect regarding the strict adherence to such procedures within sound-based music.

\section{CONTRIBUTIONS}

The call for articles was intended to prompt responses from practitioners and artists utilising sound libraries, personal and public archives and audio maps to better

${ }^{5}$ Website information for Johanas Kreidler, http://www.kreidler-net. de/productplacements-e.html (accessed 1 February 2019). understand wider perspectives of adopting sampled material into one's own aesthetic. The accessibility of such sound material presented an equally curious issue to reflect upon regarding the benefits, pitfalls or challenges associated with obtaining and using these existing sound resources. Composer, Steven Naylor documents his personal experiences of using sound archive material in his article 'Borrowed for Permanent Use: The Instruments INDIA commissions' and approaches areas of acquisition tactics and power, singularity and loss, and curation when dealing with sound borrowing of a cultural nature. Naylor reminds us that the term 'borrowing' in relation to sampling does not end, as the term suggests, with the act of returning the material to its rightful owner. The notion of borrowing within acousmatic music creation hits upon a further incompatibility, since acousmatic music fixes media content indelibly into a new configuration. A further discussion emerges in Naylor's contribution on the topic of recording practices involving cultural sound material. The means for capturing sound can be hidden or lost when sampling becomes part of a creative process. As a result, Naylor remarks that the ethics of sound sourcing can become overlooked or forgotten about where this trail of authorship is severed without thought of its creator, in this case the 28 performers of Indian musical instruments featured in the archive. Naylor covers not only his own personal anecdotes from engaging with cultural sound borrowing, but also perceptions from two other participants involved in the commission, Ish Sherawat (India) and Greg Dixon (USA), and demonstrates a very welcomed case study into the appropriateness of appropriation. This article provides a second installment to the story of the Instruments INDIA project first documented by me in the 'Sound of Cultures' issue of Organised Sound, Volume 19(2) (see Blackburn, 2014). Establishing this sound archive, through interactions with performers of Indian musical instruments, laid the foundation for Naylor's experiences of exploring sound diversity within electroacoustic music practices, along with negotiating and confronting approaches to respectful sound borrowing.

Leigh Landy's article, 'Re-composing Sounds ... and Other Things' provides an opportunity for the Editor of Organised Sound to talk from experience about sampling across a 40 -year period. This personal history sits happily in this issue, raising pertinent issues such as the politics of sound-based sampling and the subject of legalities. In this contribution, it is possible to see sampled material as a viable 'something to hold on to' component and facilitator when used in soundbased music, especially when sound identity is kept intact. The delineation of what a sample might look like seems like an obvious comment to make, but 
surprisingly this important fact is often overlooked, and we are reminded of its variability: 'a sonic sample can range from micro-sound to an entire work as well as including notes and note-based passages'. A crucial cornerstone of Landy's contribution to this issue rests upon his knowledge that most novices to sound-based music 'find abstract sounds (whether generated or manipulated sonic material) more difficult to grasp and thus enjoy than sounds they feel they find familiar'. Familiarity is certainly a key word here, not only for Landy's article, but also for the entire issue where borrowing is concerned. Being familiar with something borrowed can be a sticking point on the reception side of the discussion, however, in composition, there is a familiarity already in place - with that of the borrowed element. The article concludes with an insight about sampling's beneficial role within collaborative composition projects especially in the context of educational projects. Landy's experience as a developer of resources and tools for young people entering the world of sound-based music capitalises on this knowledge of sample use and engagement. This perspective is certainly of value across the sonic arts as a general principle.

My own article, 'The Terminology of Borrowing', attempts to get a better handle on the scale of borrowing within the electroacoustic music repertoire. Searching for examples of musical borrowing within the genre resulted in an overwhelming discovery of repertoire that far superseded the initial handful of works I originally thought existed. This piece of research yielded approximately 70 electroacoustic works all demonstrating a form of musical/sound borrowing. With so many works to consider, a tabulated display of repertoire data and terms stemming from categorisation activities appeared to fair better in conveying findings. Observing the lay-of-the-land when it comes to musical/sound borrowing in electroacoustic music showed up the common cross-wires and confusion in operation when one talks about their actions importing existing material that belongs to someone else. Composer conversations and programme notes provided the means to extract this data, enabling a framework to emerge for a) deciphering borrowing procedures and $b$ ) providing a functional template for other composers interested in engaging with borrowing as a basis for their own work. Taking the time to discuss borrowing durations, modifications, motivations and copying as borrowing fleshes out the literature contribution on these often overlooked nuances of sound transfers. The collation of terminology found in this contribution is a starting point and first attempt in bringing systemisation to a vastly sprawling area. Since the article's acceptance to this issue, I have noticed discussions on these separate areas of borrowing have already opened the door to additions and extensions. It is without a doubt that further repertoire of this kind is out there for discovery, along with further terminology. Take for example Hallowell's illumination of term 'déploration' ${ }^{6}$ and terminology belonging to inter-textuality ('travesty' and 'ennoblement' stand out as particularly useful additions with regard to the discussion on motivations for borrowing).

Taking the case study of Oval's album 94 diskont (1995), Neil O Connor takes us through an a number of sound recycling concepts both in and external to sonic arts practices in 'Material and Medium: An examination of sound recycling in Oval's 94 diskont'. This article moves away from examining borrowed content, confirming the 'source material used in [Oval's] Do While is uncredited on the album's liner notes', and instead shifts the spotlight onto technology's imprint upon creativity when recycling procedures are employed (such as the skipping CD), which 'repurposes the unlistenable ... and transforms it into something harmonious'. Viewing borrowing through concepts of 'rhizome' and 'assemblage' provide helpful ways to understand both import appearances and major restructuring of events to create something new or new sounding. Discussing borrowing procedures when sound samples are rendered 'unrecognisable', as in the case of Oval's Do While, encourages consideration for repertoire that borrows without showing, and in this situation, recasting this existing material as beautiful and distinct, yet remotely removed from its beginnings. O Connor's inclusion of technological error brings to light the little-documented issue of materiality, one which perhaps deserves its own issue of Organised Sound to fully investigate the movement of sound elements from one source to the next, together with its remnants of recording practices, media and technology. Recordings are the means by which samples enter a new context, but recorded media covers many types, each with individual qualities that can impact upon the new work. Taking Ricardo Climent's acousmatic work The Last Castrati (2005) as an example, the importance of historical recorded media comes to the fore when we are informed that the extracts used were obtained from early wax cylinder recordings of Alessandro Moreschi. In accessing samples from early recordings, a legacy is continued in the new work,

${ }^{64}$ Déploration may be more accurately defined as a mode of communal commemoration' (Hallowell, 2013: Abstract). 'Fragments of a departed composer's music were often incorporated into posthumous tributes thereto; traditions of elaborating polyphonic masses on monophonic tunes' (Hallowell, this issue).

${ }^{7}$ DDefined as the rewriting of some "noble" text as a new text that retains the fundamental content but presents is in another style in order to “debase it” (Genette, 1997: 58)' (Lacasse 2000: 42).

${ }^{8}$ This being the opposite of 'travesty', leading to greater nobility through elevated status. 
together with perhaps a greater connectivity with music recording's historical past.

Staying on the topic of materiality, Mike Glennon's article 'Consumer, Producer and Curator: The mixtape as creative form' provides a blast from the past with his discussion of mixtapes and their dependency upon 'borrowed, repurposed and re-contextualised material'. Uniquely this article delves into the historical and political uses of tape recording. Assessing public uptake of the mixtape as a device for homepiracy, in opposition to the music industry's battle for fixity in the shape of $\mathrm{CD}$ sales, lies a reminder of the versatile, tactile, wipe-clean-and-start-again media readers of certain age will certainly have some fondness and nostalgia for. Borrowing is a necessity within mixtape creativity, while the art and curatorial care in this practice belongs to the selection and ordering stages of the process, generating a bespoke personalised playlist. Curating as borrowing stresses the broad interpretations of the issue's theme, facilitating a way for mixtape makers to possess music for repeat listening or as a away of 'gifting' music to others.

Glennon presents instances of the contemporary mixtape, documenting its utilisation in the post stream-age years as a comment on the value of cassette as hardcopy artefact, beyond download culture. Highlighted in this contribution is the opportunity the cassette still affords an enduring and revivalist site for experimentation, curation and DJ culture expression. Borrowing and/ or sampling in traditional mixtape creations carves out a peculiar aesthetic and niche for those practitioners mentioned in this text. When reading Glennon's article, one recalls the work of Jansen (2009: 43) and his reminder that 'old cassette mix tapes tend to bring back memories' along with their ability to conjure up 'a wealth of autobiographical memories related to a specific tape, mix tapes naturally trigger memories of the outdated technology of the cassette recorder and of spending many an hour mixing tapes'. Memory and borrowing as a paired theme is certainly an avenue for further investigation when viewing borrowing as a process integrating something previously heard into a new form. The existing material, lodged in our memory from an initial encounter with it, can be recalled through auditioning the new form, something Milsom (2018: 325) terms 'simultaneous listening' in reference to his observations of borrowing in parody masses of the sixteenth century. Looking back to music and analyses of the Renaissance and Baroque times may seem like a distant or unrelated resource to draw upon for ideologies and concepts of borrowing procedures; however, terminology and insights are both plentiful due to the frequency and propensity of borrowing activity during this early music period (e.g., derivative masses and madrigals). Acclimatising oneself with borrowing concepts of differing musical genres and styles - for example, hip-hop, chart remixes, jazz arrangements or fifteenth-century quodlibet to name a few - is a viable means to open out the discussion on borrowing procedures, especially when the borrowings enters the sonic arts from distant times, cultures and forms.

Burkholder reminds us that there is much to be gained 'by approaching the uses of existing music as a field that crosses periods and traditions' (1994: 851), which is both applied and verified in Sean Russell Hallowell's writing in 'Towards a Phenomenology of Musical Borrowing', who considers two repertoires that 'stand out for their exemplary embrace of borrowing practices - Medieval Polyphony and musique concrète'. This article attempts to reveal what the beginnings of Western compositional tradition can tell us about musical borrowing stating that 'scholars have long chronicled how composers of the thirteenth to seventeenth centuries habitually adapted elements from pre-existent works in making their "own" music'. Hallowell's return to the medieval concept of auctoritas, which encapsulated 'the invocation of some precedent authority to legitimate one's own work', reinstates the originality argument introduced earlier in this editorial. This article finds it feet in drawing comparisons between early music and musique concrète when considering concepts of 'compositional originality, the aesthetic idea, and musical materiality'. A line that cuts through this text plainly states, 'in Schaeffer's conception, then, as in the conceptions of Binchois, Power and Ockeghem musical composition consists in the elaboration of pre-existent material, be it a notated cantus firmus or a recorded sound object'. Here we see an acceptance that to compose is to borrow. The example of Schaeffer's early experiments with sound, including his Etude aux chemins de fer (1948), provides a way of viewing sound recording (of trains in this case) as an instance of musical borrowing. This text concludes with some refreshing thoughts on the value of musical borrowing, its ethics and the notion that 'to borrow is to borrow something from someone'.

The subject of shared knowledge of musical borrowing is broached in Nuria Bonet's 'Musical Borrowing in Sonification'. This article proves how borrowing in instrumental music can be shaped by sonification of data, demonstrating the benefit of tapping into audience familiarity with original works as a means of a 'more effective transmission'. The contributor's instrumental work, Wasgiischwashäsch (2017), which makes use of Rossini's William Tell Overture (1829), is presented as a case study to view how datasets relating to climate change in Switzerland can be sonified in the instrumental domain. This work is framed as an 'orchestral sonification, where the mappings and 
transformations are applied to the original score rather than a recording' and where the score is 'composed 'manually' rather than by a computer program'. Mapping of data is a central concern for Bonet's discussion, which draws upon telecommunication theory as a way of bypassing the learning stage common to applications of sonification within a musical work.

As Bonet stands by the notion that 'familiarity with the original work will ... increase the appreciation of the compositional process and extra-musical meaning of the new work', the topic of appreciating the borrowing, sampling or quotation lingers in the air, reminding us of Landy's earlier considerations of familiarity together with its reception and pedagogical benefits.

Franco Degrassi's article 'Some Reflections of Borrowing in Acousmatic Music' provides an opportunity for the practitioner's viewpoint to emerge. Questions arise over why a composer might look to existing music to form new work in the first place and what new knowledge might be gained from experimentation with this existing material. These lines of enquiry encourage Degrassi's reflections on his own practice commenting on the specifics of cultural citation and categorisations of borrowing types. Degrassi's repertoire examples provide a very welcomed extension on the wider understanding of borrowing in electronic music's historical past. Considering the works by Henry, Xenakis, Ferrari, Maderna, Stockhausen and Ceccarelli demonstrate the proliferation of borrowing procedures in this early period, further confirming such practices as widespread, frequent and viable. Degrassi urges us to consider cultural citation as an inheritance process of musical history, schools of musical practice and overall themes of music making.

Two off-theme articles appear within this issue of Organised Sound, the first is by Danilo Rossetti and Jônatas Manzolli entitled 'Analysis of Granular Acousmatic Music: Representation of sound flux and emergence'. This article draws attention to graphical representations of works employing considerable granular techniques and examines the handling of sound flux and emergent timbre as a focal point. This contribution studies how 'the interactions among grains which occur in the microtime domain (under 100 milliseconds) result in a macrostructure (perceived timbre) that exhibits new properties not shared by the isolated grains'. Works from Xenakis, Truax and Vaggione are used as case studies for exploring phenomena related to sound flux in granular compositions.

Luc Döbereiner's article 'Towards a Materialist Conception of Sound as Thing' offers a philosophical discussion drawing on several philosophers' voices challenging Schaeffer's objet sonore 'an ideal unity constituted by a subject's intentionality and attempts to rethink experimentation as a practical form of thought that takes place through interaction with sonorous material' thus outlining 'a conception of sound as a non-symbolic otherness'. In other words, the author is suggesting a 'thingness' of a sound that exists independently of perception thus 'shift[ing] attention to relational processes of material individuation that give rise to sonic identities'. The author suggests: 'Perceived sonorous identity is brought forth not by recognising spectromorphological archetypes but by active, situated, and inventive ways of relating to the world. A sound is thus no given entity that can be isolated.' His interest is to seek 'an openness towards the contingency of the material' as opposed to either a sound's 'phenomenological or [its] technical reduction'.

To conclude this editorial, I would like to thank Raúl Minsburg for his help, support and motivation when preparing the call for articles. I would also like to thank all reviewers involved in the process for their commitment, attention to detail and their input as part of the peer review process, ultimately shaping the outcome of this issue.

Manuella Blackburn (manuellablackburn@gmail.com)

\section{REFERENCES}

Blackburn, M. 2014. Instruments INDIA: A Sound Archive for Educational and Compositional Use. Organised Sound 19(2): 146-53.

Burkholder, P. 1994. The Uses of Existing Music: Musical Borrowing as a Field. Notes 50(3), 851-70.

Genette, G. 1997. Palimpsests: Literature in the Second Degree. Lincoln, NE: University of Nebraska Press.

Hallowell, S. 2013. The Déploration as Musical Idea. PhD dissertation, Columbia University.

Jansen, B. 2009. Tape Cassettes and Former Selves: How Mix Tapes Mediate Memories. In K. Bijsterveld and J. van Dijck (eds.) Sound Souvenirs: Audio Technologies, Memory and Cultural Practices. Amsterdam: Amsterdam University Press, 43-53.

Lacasse, S. 2000. Intertextuality and Hypertextuality in Recorded Popular Music. In Michael Talbot (ed.) The Musical Work. Liverpool: Liverpool University Press.

Milsom, J. 2018. T-Mass: quis scrutatur? Early Music 46(2): 319-31.

\section{DISCOGRAPHY}

Climent, R. 2005. The Last Castrati. On ICMC 2005: Free Sound, ICMA-CD.

Parmerud, A. 2016. Necropolis: City of the Dead (2011). On Necropolis. Montreal: Empreintes Digitales, IMED16137-CD.

Schaeffer, P. 1979. Étude aux chemins de fer (1948). On Pierre Schaeffer L'oeuvre musicale. Paris: Ina GRM, INA C $1006 / 7 / 8-C D$ 